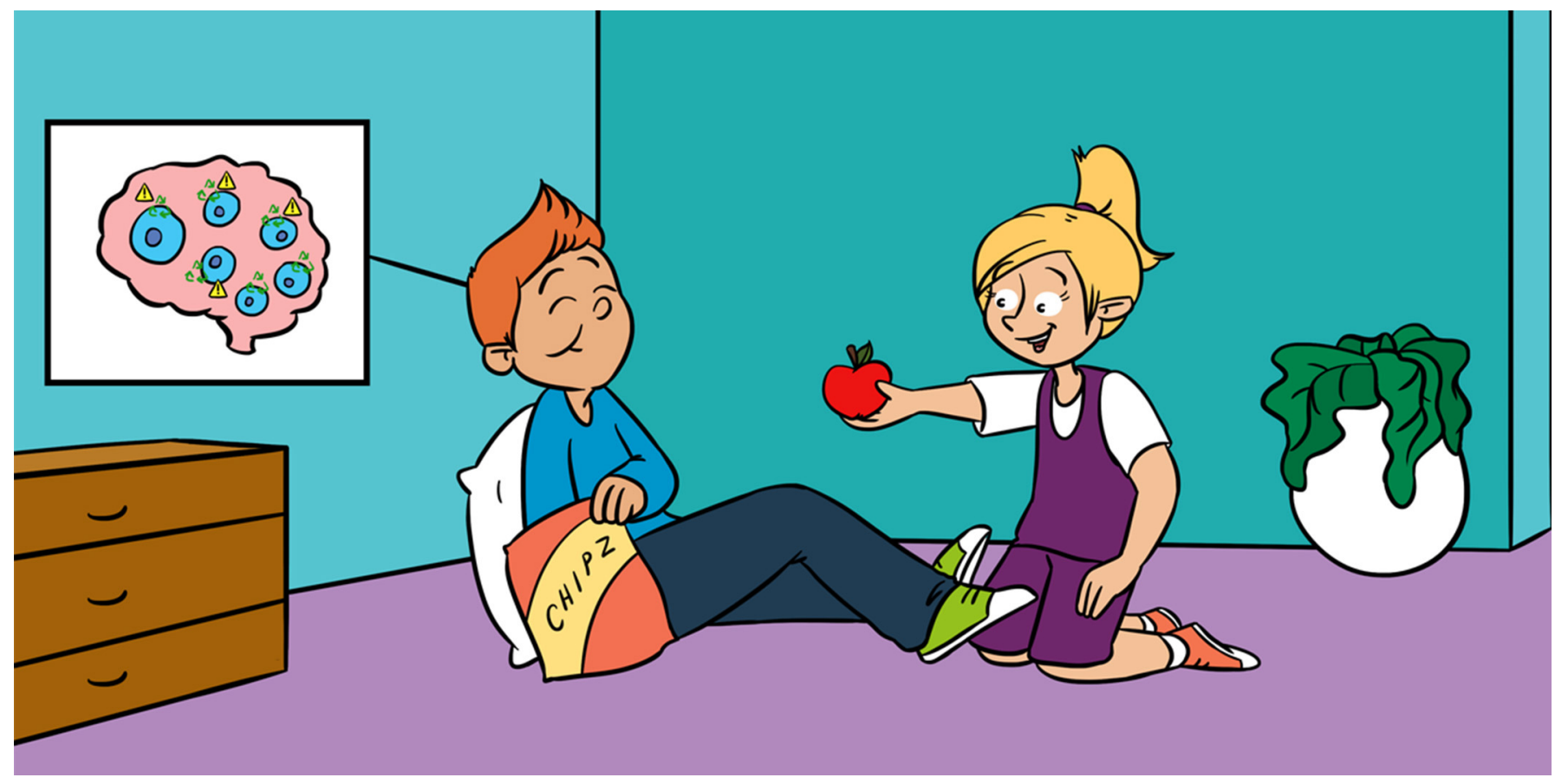

\title{
THE RECYCLING SYSTEM IN CELLS THAT HELPS TO PREVENT OBESITY
}

\section{Carla Narro ${ }^{\dagger}$, Patricia Rivera $^{\dagger}$ and Eugenia Morselli ${ }^{*}$}

Laboratory of Autophagy and Metabolism, Department of Physiology, Faculty of Biological Sciences, Pontificia Universidad Católica de Chile, Santiago de Chile, Chile

YOUNG REVIEWERS:

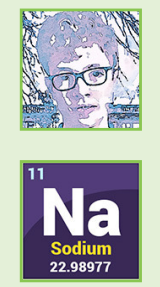

JOHANNES

AGE: 13

FABIO

AGE: 16

\section{AUTOPHAGY}

The cellular process that collect

unnecessary or old cellular components either to removed them, through a process of degradation, or to recycle them to build new cellular components.
Our cells have their own recycling center! Autophagy is the name of this amazing process, which allows cells to recycle cellular components to generate new ones and to provide energy for cell survival. If we eat too much high-fat food, autophagy might start malfunctioning in specific parts of the brain, and this can contribute to the development of obesity. Therefore, eating healthy food is important, so we can keep autophagy working properly and prevent obesity!

\section{AUTOPHAGY: THE WASTE-RECYCLING SYSTEM OF OUR CELLS}

Within our cells, many processes occur simultaneously. Various cellular components work together to maintain the cells and keep the body healthy. However, these cellular components can get old and in need of replacing, or they can accidentally get damaged. When this happens, the "waste alert" within the cell turns on, and a process called autophagy comes into action. Autophagy is a process that occurs in the cytoplasm of cells. The mission of autophagy is to collect cellular 
Figure 1

Autophagy in action.

"Autophagy Man"

(yellow) wakes up

when he has a mission:

to collect cell waste

and deliver it to the

recycling center.

Autophagy Man begins

to capture damaged

cell parts and aging

proteins into his

phagophore, then he

wraps them in a double

membrane called an

autophagosome. Once

filled with the material

that must be removed,

the autophagosome

reaches the lysosome

and fuses with it,

generating a new

structure called the

autolysosome. This is

where the degradation

of the cargo occurs,

resulting in the

generation of energy

and the production of

new cellular

components.

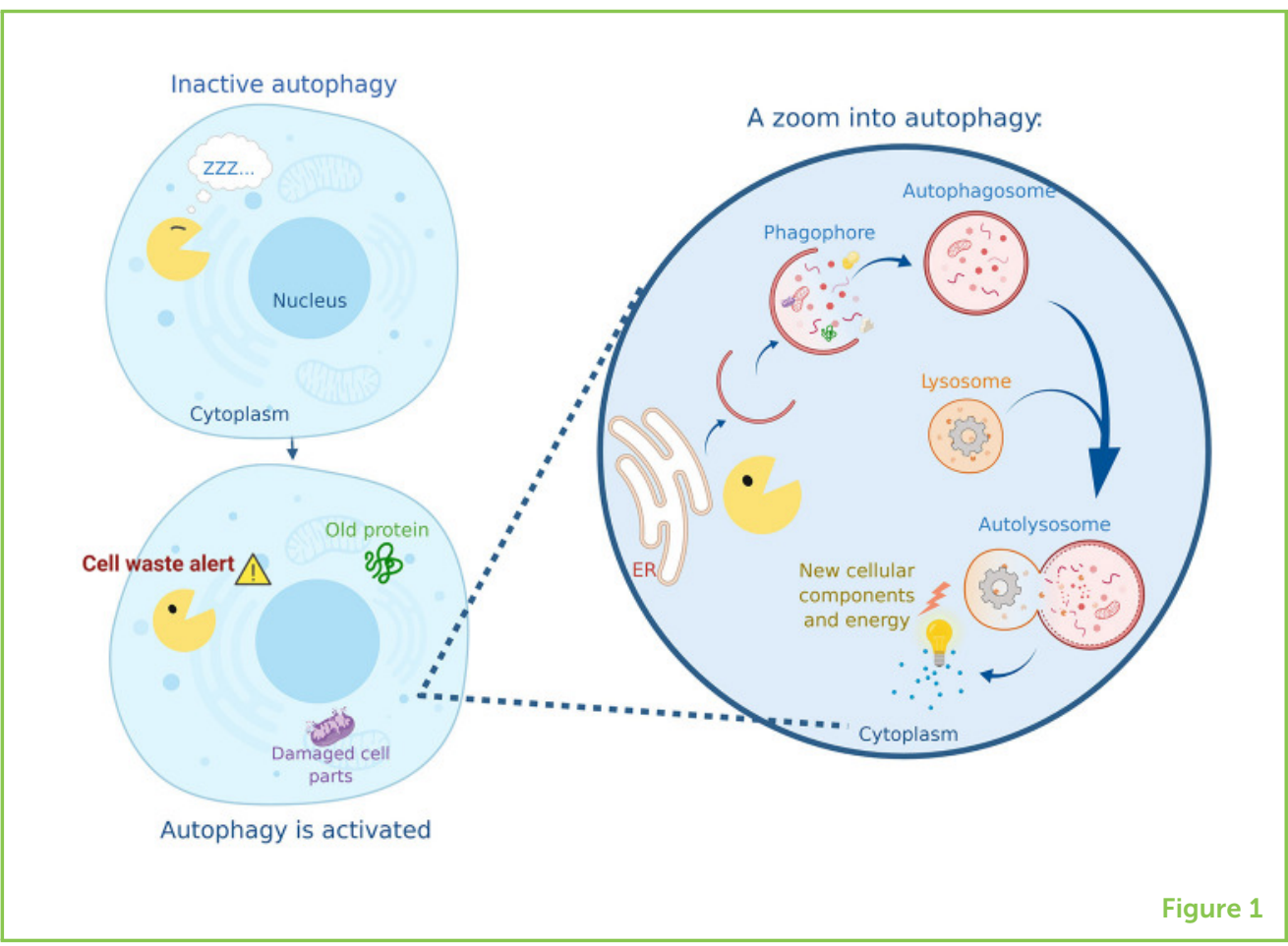

waste and to deliver it to the cell's recycling center, where the waste can be used to generate energy or to make new cellular components from old ones. Without autophagy, cells would die from the negative effects of waste accumulation.

Autophagy consists of several steps. The structures that form in these steps may have complicated names, but you can easily follow the process in Figure 1. First, the cell's endoplasmic reticulum donates a piece of its membrane to form a structure called a phagophore. The phagophore begins to enclose the cellular waste, including old or damaged cell parts and proteins. The phagophore then totally closes up around the waste, forming a spherical structure called an autophagosome. You can imagine this process as a soap bubble forming around the waste material that needs to be recycled. The autophagosome travels to the recycling factory of the cell: the lysosome. The fusion of the lysosome with the autophagosome forms the autolysosome, where the magic happens. Specialized proteins from the lysosome break down the cellular waste to generate new material that will be used to build new cellular components and to create energy.

\section{AUTOPHAGY SAVES OUR CELLS WHEN THERE IS NO FOOD!}

Since our cells are always working and wearing out, autophagy is always occurring. However, autophagy may work more than usual in certain situations, for example when cells are in conditions of 
Figure 2

Autophagy helps cells that are experiencing starvation or nutrient deprivation. When a low energy alert is activated in the cell, Autophagy Man must collect stores of nutrients inside the cell, such as carbohydrates, proteins, and lipids, and bring them to the recycling center, where he fuses with a lysosome. The broken-down nutrients are then converted into energy that the cell can use to survive.

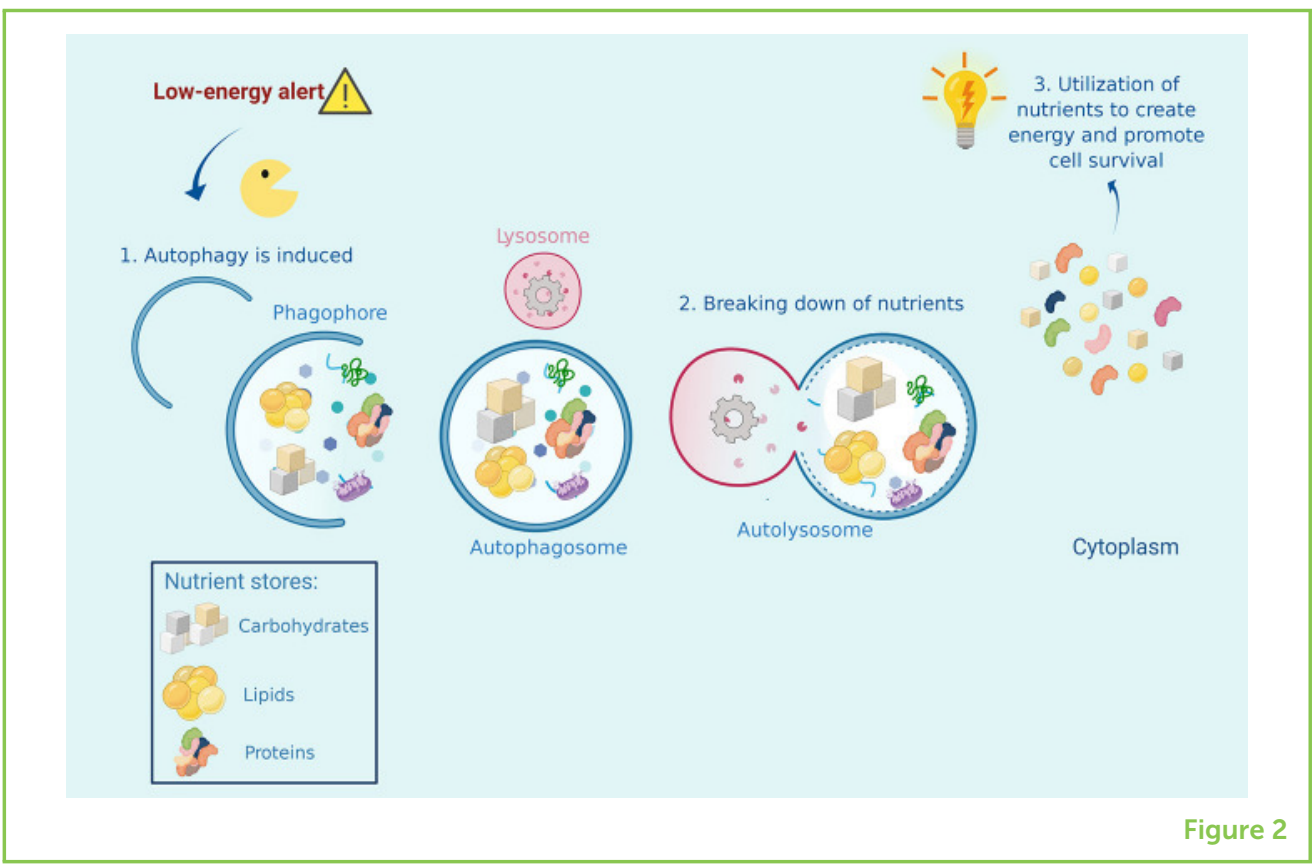

starvation or nutrient deprivation. Our bodies and cells normally receive energy through the foods we eat. The nutrients from the carbohydrates, fats, and proteins that we ingest are either transformed directly into the energy needed for bodily functions and physical activity or, if they are not immediately needed, the nutrients are stored in our cells until the body requires them.

When we skip meals, for example during a period of fasting, we are not taking energy and nutrients into our bodies. A low-energy alert turns on within our cells and stimulates autophagy, which supplies the energy that is not being provided by food. Autophagy accomplishes this by breaking down the cell's nutrient stores, which are then used to obtain energy. In this emergency situation, autophagy is still recycling cell waste, but it will prioritize the breakdown of nutrient stores to meet the energy requirements of our cells. In this way, autophagy maintains energy balance in the body and prevents cells from dying of starvation (Figure 2) [1].

\section{OVEREATING STOPS AUTOPHAGY IN THE BRAIN}

Now we know that autophagy senses the decrease in incoming nutrients that indicates starvation. Importantly, autophagy also senses overeating! What happens when we eat too much? If we eat more than our bodies need, autophagy can malfunction and this may contribute to the onset of obesity. This is worrying because obesity is currently an epidemic in some countries. The latest report from the World Health Organization indicates that, in 2016, 39\% of adults worldwide were overweight, while $13 \%$ were obese. And rates are only getting higher each year! 
Figure 3

Autophagy

regulates how much

animals eat. (A) In

healthy conditions,

eating stimulates the

release of insulin from

the pancreas. Once the

hypothalamus receives

the signal transmitted

by insulin, it

understands that the

body has received

enough food, and

specialized brain cells

send a "stop eating"

signal. (B) A high-fat

diet causes the

accumulation of

saturated fats in the

brain. This built-up fat

inhibits Autophagy

Man's super-powers,

and brain cells lose the ability to recognize

insulin's message. This

causes the mice to eat

more than they need.

\section{SATURATED FATS}

An unhealthy type of dietary fat that can

cause several diseases

if eaten in excess.

\section{HYPOTHALAMUS}

Hypothalamus is a

brain region that

regulates sleep cycles

(when to sleep), body

temperature, food

intake (when to eat and

spot eating), and other

nervous system

functions.

INSULIN

A hormone (signaling molecule) that is released into the bloodstream from the pancreas after eating, causing the

hypothalamus to send an "I am full" message.

\section{SATIETY}

The feeling of being full, which indicates that the body has no immediate need to eat.

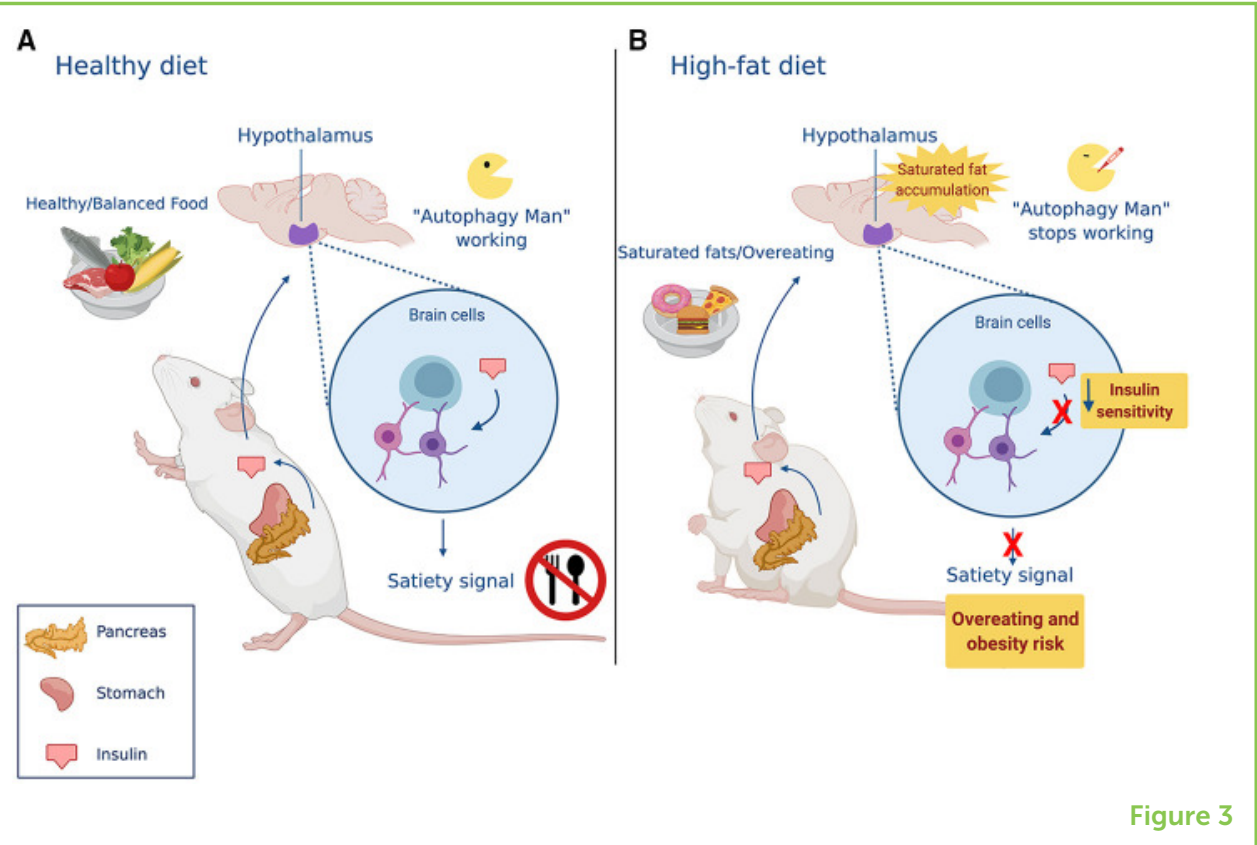

To understand the relationship between autophagy and obesity, we must first know that one of the main contributors to increasing obesity rates is the overconsumption of foods rich in saturated fats. An increased concentration of saturated fats in our bodies can cause several different diseases. Saturated fats from high-fat diets can accumulate in the brain and affect its function [2-4]. Let us focus our attention on the hypothalamus, a region of the brain involved in the regulation of appetite. When saturated fats accumulate in the cells of the hypothalamus, the normal regulation of appetite is lost.

How does this happen? In the hypothalamus, a group of specialized brain cells normally knows when we are hungry or full because they receive information from other parts of the body through chemical messengers, like insulin. When we eat, insulin is released from the pancreas and travels through the blood to the brain, informing cells in the hypothalamus that the body has enough food. In response to insulin, the hypothalamus produces a satiety ("I am full!") signal that causes us to stop eating.

Since it is complicated to study the brain in humans, scientists (including us!) have studied mice to understand how saturated fats affect autophagy in the brain, thereby altering the regulation of appetite, for more information see "From Mice to Humans: The Study of Obesity" [5]. We have seen that, when mice chronically consume high-fat diets (for 16 weeks), saturated fats accumulate in their brains [6]. Autophagy takes place to try to keep the fat in check. Imagine autophagy in a battle against fat accumulation, fighting to break down the excess fat stores. Unfortunately, if there is too much fat, autophagy will lose. Once this happens, autophagy is inhibited, which means that it will no longer be able to fight against fat accumulation. Fat 


\section{PALMITIC ACID}

Palmitic acid is the most common saturated fat, we find it in foods such as meats, cheeses, vegetable oils and others. accumulation will eventually cause damage to brain cells, preventing their ability to sense insulin, and the hypothalamus will no longer give the satiety signal [7]. As a consequence, more and more food is consumed, eventually leading to obesity (Figure 3).

There are many different types of saturated fats and we do not know if all of them can turn off autophagy in the hypothalamus. In our lab, we tested palmitic acid, which is the most common saturated fat found in most high-fat diets. Palmitic acid can be found in foods like red meat, dairy, butter, and palm oil. Using cell cultures of hypothalamic cells, our experiments showed that palmitic acid inhibits autophagy and reduces the cells' ability to detect insulin [8].

\section{WHAT ABOUT THE FUTURE?}

Autophagy is an essential process in all cells. While its primary function is breaking down cellular waste, it also regulates the cellular response to nutrients. In summary, the consumption of a high-fat diet causes an accumulation of saturated fats in the brains of mice, inhibiting autophagy in the cells of the hypothalamus. When autophagy stops, these brain cells can no longer respond to insulin nor give the satiety signal. We hypothesize that the same is happening in humans [5], however future research is needed to confirm that this is the case.

The excessive consumption of saturated fats is detrimental to our health. Today's treatments for obesity do not consider the role that saturated fats, such as palmitic acid, might be playing. Furthermore, obesity treatments do not consider the role of autophagy. Failure to take these important processes into account could explain the limited effectiveness of many obesity treatments. Drugs that can manage obesity by regulating autophagy have been identified in animals and there are ongoing tests to determine whether these drugs also work in humans. Once we fully understand how saturated fats affect autophagy in the brain cells that regulate appetite, we may be able to develop new therapies that help autophagy to work better when fat accumulates in the brain. Such treatments would save many lives and would help to slow the world's worsening obesity epidemic.

\section{ACKNOWLEDGMENTS}

This work was founded by grants from Fondo Nacional de Desarrollo Científico y Tecnológico, FONDECYT 1200499 to EM and by the CONICYT PIA 172066 to EM. Figures have been realized using the program BioRender. The authors thank everyone in the Morselli lab for constructive discussions and criticisms. 


\section{REFERENCES}

1. Kim, K. H., and Lee, M. S. 2014. Autophagy-a key player in cellular and body metabolism. Nat. Rev. Endocrinol. 10:322. doi: 10.1038/nrendo.2014.35

2. Karmi, A., Iozzo, P., Viljanen, A., Hirvonen, J., Fielding, B. A., Virtanen, K., et al. 2010. Increased brain fatty acid uptake in metabolic syndrome. Diabetes 59:2171-7. doi: 10.2337/db09-0138

3. Valdearcos, M., Robblee, M. M., Benjamin, D. I., Nomura, D. K., Xu, A. W., and Koliwad, S. K. 2014. Microglia dictate the impact of saturated fat consumption on hypothalamic inflammation and neuronal function. Cell Rep. 9:2124-38. doi: 10.1016/j.celrep.2014.11.018

4. Morselli, E., Criollo, A., Rodriguez-Navas, C., and Clegg, D. J. 2014. Chronic high fat diet consumption impairs metabolic health of male mice. Inflamm Cell Signal. 1:e561.

5. Weiskirchen, S., Weiskirchen, R., and Weiper, K. 2020. From mice to humans: the study of obesity. Front. Young Minds. 8:92. doi: 10.3389/frym.2020.00092

6. Rodriguez-Navas, C., Morselli, E., and Clegg, D. J. 2016. Sexually dimorphic brain fatty acid composition in low and high fat diet-fed mice. Mol. Metab. 5:680-9. doi: 10.1016/j.molmet.2016.06.014

7. Meng, Q., and Cai, D. 2011. Defective hypothalamic autophagy directs the

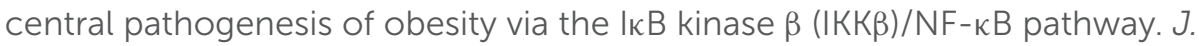
Biol. Chem. 286:32324-32. doi: 10.1074/jbc.M111.254417

8. Hernández-Cáceres, M. P., Toledo-Valenzuela, L., Díaz-Castro, F., Ávalos, Y., Burgos, P., Narro, C., et al. 2019. Palmitic acid reduces the autophagic flux and insulin sensitivity through the activation of the free fatty acid receptor 1 (FFAR1) in the hypothalamic neuronal cell line N43/5. Front. Endocrinol. 10:176. doi: 10.3389/fendo.2019.00176

SUBMITTED: 11 August 2020; ACCEPTED: 29 October 2021; PUBLISHED ONLINE: 22 November 2021.

EDITED BY: Kylie Belchamber, University of Birmingham, United Kingdom

CITATION: Narro C, Rivera P and Morselli E (2021) The Recycling System in Cells That Helps to Prevent Obesity. Front. Young Minds 9:593935. doi: 10.3389/frym. 2021.593935

CONFLICT OF INTEREST: The authors declare that the research was conducted in the absence of any commercial or financial relationships that could be construed as a potential conflict of interest.

COPYRIGHT (c) 2021 Narro, Rivera and Morselli. This is an open-access article distributed under the terms of the Creative Commons Attribution License (CC BY). The use, distribution or reproduction in other forums is permitted, provided the original author(s) and the copyright owner(s) are credited and that the original publication in this journal is cited, in accordance with accepted academic practice. No use, distribution or reproduction is permitted which does not comply with these terms. 

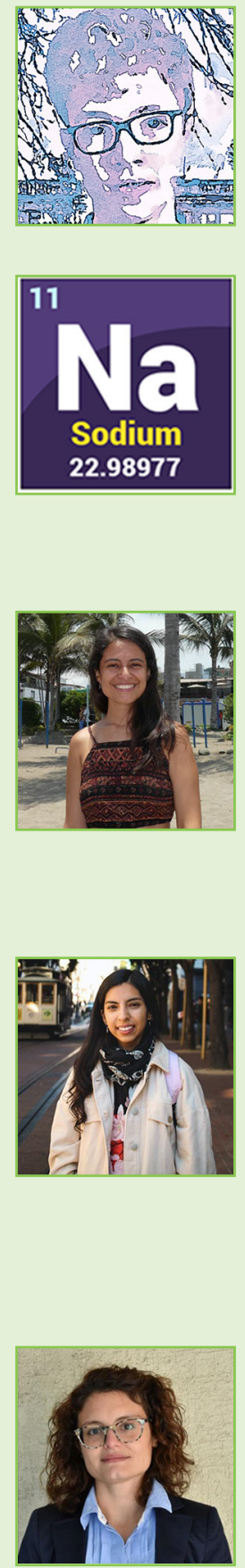

\section{YOUNG REVIEWERS}

\section{JOHANNES, AGE: 13}

I am very interested in science and it is very interesting to review these papers from real scientists who know very much about their specialized fields! Many of the papers explain very dangerous illnesses for the human population to children, and I think these information are important to know!

\section{FABIO, AGE: 16}

$\mathrm{Hi}$, I am Fabio and many people give me the funny surname of "chemical master" for doing some crazy experiments. In my free time and holidays, I like to go to the beautiful beaches that are very close to my city with my parents.

\section{AUTHORS}

\section{CARLA NARRO}

I am a Peruvian biologist currently working as a research assistant in the Laboratory of Autophagy and Metabolism at the Pontificia Universidad Católica de Chile. Soon, I will start a master's program in life sciences and health. My interest lies in understanding how altering cellular processes leads to the development of diseases. In my free time, I love running and connecting with nature through camping and hiking.

\section{PATRICIA RIVERA}

I am a biochemist, currently working as a research assistant at the Pontificia Universidad Católica de Chile in Santiago de Chile. Due to the increase in obesity in the world, I have a keen interest in studying cellular processes that are affected by the consumption of high-fat diets. In my undergraduate thesis, I studied the damage caused by obesity on the kidneys and now I am working on how fatty acids affect autophagy in hypothalamic neurons. Outside the laboratory, I enjoy taking pictures, playing guitar, and traveling.

\section{EUGENIA MORSELLI}

I am a biotechnologist currently working as an associate professor at the Pontificia Universidad Católica de Chile in Santiago de Chile. The research we are developing in our laboratory focuses on understanding how consumption of a high fat diet affects autophagy, leading to obesity. Through this knowledge, we want to establish new therapies to treat obesity and obesity-associated diseases. In addition to my passion for science, I love gardening, cooking, and traveling. *emorselli@bio.puc.cl

${ }^{\dagger}$ These authors have contributed equally to this work 